\title{
Empirical formula for the refractive index of freezing brine
}

\section{Frisvad, Jeppe Revall}

\section{Published in:}

Applied Optics

Link to article, DOI:

10.1364/AO.48.002149

Publication date:

2009

Document Version

Publisher's PDF, also known as Version of record

Link back to DTU Orbit

Citation (APA):

Frisvad, J. R. (2009). Empirical formula for the refractive index of freezing brine. Applied Optics, 48(11), 21492153. https://doi.org/10.1364/AO.48.002149

\section{General rights}

Copyright and moral rights for the publications made accessible in the public portal are retained by the authors and/or other copyright owners and it is a condition of accessing publications that users recognise and abide by the legal requirements associated with these rights.

- Users may download and print one copy of any publication from the public portal for the purpose of private study or research.

- You may not further distribute the material or use it for any profit-making activity or commercial gain

- You may freely distribute the URL identifying the publication in the public portal

If you believe that this document breaches copyright please contact us providing details, and we will remove access to the work immediately and investigate your claim. 


\title{
Empirical formula for the refractive index of freezing brine
}

\author{
Jeppe Revall Frisvad \\ Department of Informatics and Mathematical Modelling, Technical University of Denmark, Richard Petersens Plads, \\ DTU-Building 321, DK-2800 Lyngby, Denmark (jrf@imm.dtu.dk)
}

Received 12 January 2009; revised 18 March 2009; accepted 19 March 2009; posted 20 March 2009 (Doc. ID 106212); published 6 April 2009

\begin{abstract}
The refractive index of freezing brine is important in order to, for example, estimate oceanic scattering as sea ice develops. Previously, no simple continuous expression was available for estimating the refractive index of brine at subzero temperatures. I show that extrapolation of the empirical formula for the refractive index of seawater by Quan and Fry [Appl. Opt. 34, 3477 (1995)] provides a good fit to the refractive index of freezing brine for temperatures above $-24{ }^{\circ} \mathrm{C}$ and salinities below $180 \%$. (C) 2009 Optical Society of America

OCIS codes: $\quad 010.4450,010.7340,160.4760$.
\end{abstract}

\section{Introduction}

Pockets of brine in freezing equilibrium constitute an important scattering inclusion in sea ice. Consequently, the temperature and wavelength dependence of the refractive index of freezing brine, $n_{\text {brine }}$, is important if we want to compute the scattering properties of sea ice using, for example, LorenzMie theory.

Quan and Fry [1] found an empirical formula for computing the real part of the refractive index of pure water or brine as a function of salinity $S$, temperature $T$, and wavelength $\lambda$. It is as follows [1]:

$$
\begin{aligned}
n_{\text {brine }}^{\prime}(\lambda, T, S)= & 1.31405+\left(n_{1}+n_{2} T+n_{3} T^{2}\right) S \\
& +n_{4} T^{2}+\frac{n_{5}+n_{6} S+n_{7} T}{\lambda}+\frac{n_{8}}{\lambda^{2}}+\frac{n_{9}}{\lambda^{3}} .
\end{aligned}
$$

The coefficients are listed in Table 1. This formula describes the dependency of $n_{\text {brine }}^{\prime}$ (the prime indicates that it is only the real part) on salinity in the range of $0 \% \circ<S<35 \%$, temperature in the range $0^{\circ} \mathrm{C}<T<30^{\circ} \mathrm{C}$, and wavelength in the range $400 \mathrm{~nm}<\lambda<700 \mathrm{~nm}$. Moreover, Huibers [2]

0003-6935/09/112149-05\$15.00/0

(C) 2009 Optical Society of America reported that the same formula is valid over a broader spectrum of wavelengths $(200 \mathrm{~nm}<\lambda<1100 \mathrm{~nm})$ than originally assumed.

\section{Previous Work}

Brine inclusions in ice have temperatures below $0{ }^{\circ} \mathrm{C}$, so we need a formula that is valid for a wider range of temperatures. Typical sea water freezes when temperatures get below $-2{ }^{\circ} \mathrm{C}$. Then brine and ice is a mixed phase system. When the system is in phase equilibrium, there is a specific relation between the temperature and the salinity of the brine. This means that one can find a formula for the refractive index of brine in freezing equilibrium that depends on temperature and wavelength alone.

Maykut and Light [3] found a way to estimate the real part of the refractive index of brine $n_{\text {brine }}^{\prime}$ in freezing equilibrium with temperatures between $-32{ }^{\circ} \mathrm{C}$ and $-2{ }^{\circ} \mathrm{C}$. The expression they propose fits their measurements well, but it is based on the Lorentz-Lorenz relation and it requires a density estimate for the brine as well as mass-weighted molar refractivities for the principal constituents of standard seawater in freezing equilibrium. Unfortunately, this way of finding $n_{\text {brine }}^{\prime}$ does not simplify to a continuous empirical formula. It involves a lot of tabulated data. In the following, I will briefly recap what is needed to estimate $n_{\text {brine }}^{\prime}$ using the method of Maykut and Light [3]. 
Table 1. Coefficients for the Empirical Formula (1) by Quan and Fry [1]

\begin{tabular}{lcc}
$n_{1}=1.779 \cdot 10^{-4}$ & $n_{4}=-2.02 \cdot 10^{-6}$ & $n_{7}=-0.00423$ \\
$n_{2}=-1.05 \cdot 10^{-6}$ & $n_{5}=15.868$ & $n_{8}=-4382$ \\
$n_{3}=1.6 \cdot 10^{-8}$ & $n_{6}=0.01155$ & $n_{9}=1.1455 \cdot 10^{6}$ \\
\hline
\end{tabular}

To compute the refractive index of brine at wavelength $\lambda$ and temperature $T$ using the LorentzLorenz relation, we need the total polarizability $P$ of the brine as a function of $T$ and $\lambda$. Then we have

$$
n_{\text {brine }}^{\prime}(\lambda, T)=\left(\frac{1+2 P(\lambda, T)}{1-P(\lambda, T)}\right)^{1 / 2}
$$

The total polarizability $P$ is given by

$$
P(\lambda, T)=\rho_{\text {brine }}(T) \sum_{i} \frac{m_{i}(T) R_{i}(\lambda) / W_{i}}{\sum_{i} m_{i}(T)},
$$

where $\rho_{\text {brine }}$ is the density of the brine and the sum is over the mass-weighted molar refractivities of the constituents $i$ with molar refractivity $R_{i}$ (in milliliters/mole), molecular weight $W_{i}$ (in grams/mole), and mass $m_{i}$ (in grams).

The data needed as input for this expression include the masses and molar refractivities of the constituents of the brine as well as the density of the brine. The masses $m_{i}(T)$ of the different constituents in equilibrium at different temperatures are available as tabulated data from Richardson [4]. The molar refractivity $R_{\mathrm{H}_{2} \mathrm{O}}(\lambda)$ of pure water as an empirical function of wavelength is available from Schiebener et al. [5]. The refractivities $R_{i}$ for the remaining constituents are reproduced by Maykut and Light [3] from data measured by Stelson [6], and they are considered independent of wavelength. All refractivities are considered independent of temperature (in the considered temperature interval). For convenience, the constant molar weights of the different constituents are also provided by Maykut and Light [3]. Finally, the density of the brine is needed and, based on their measurements, Maykut and Light give two different options: a parabolic, two-piece, least-squares fit of their density measurements or a regression fit for temperature correction of the density data measured by Thompson and Nelson [7]. A third option is to use the Thompson and Nelson data without the temperature correction.

The results obtained if one computes $n_{\text {brine }}^{\prime}$ using these mass-weighted molar refractivities and the three different options to obtain a density estimate are reproduced in Fig. 1 . The curves are quite a good fit to the measurements by Maykut and Light [3] ,

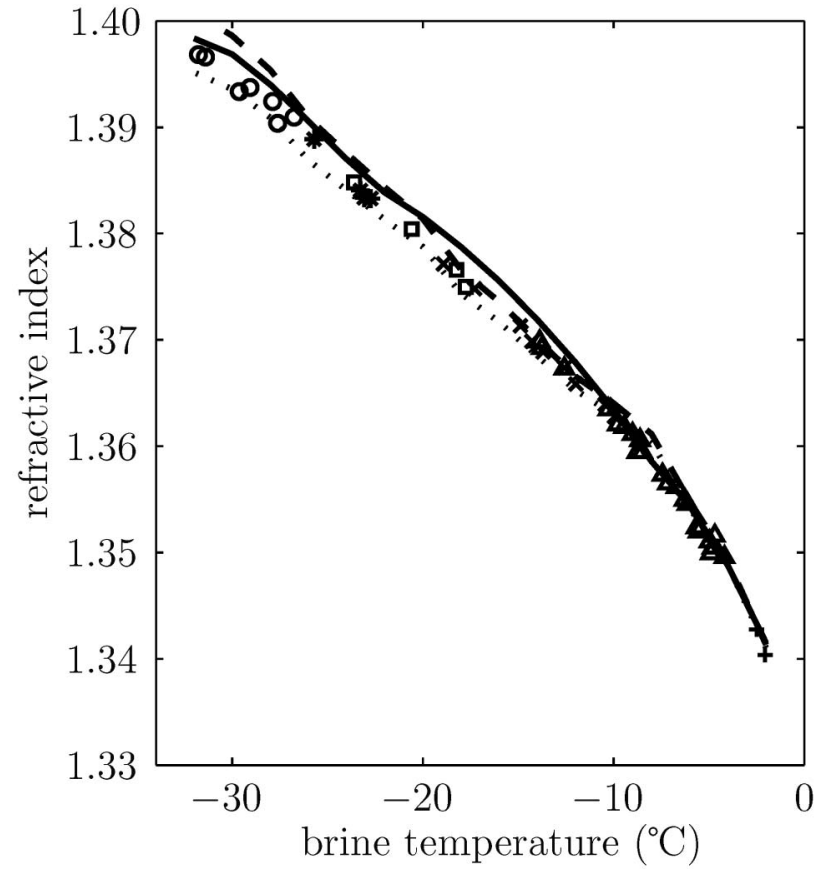

Fig. 1. Refractive index at $589 \mathrm{~nm}$ of brine in freezing equilibrium as measured by Maykut and Light [3]. Samples from six solutions are plotted; each solution has its own symbol. The three curves are the values predicted by the Lorentz-Lorenz relation with the density measured by Maykut and Light [3] (solid curve), Thompson and Nelson [7] (dotted curve), and Thompson and Nelson with a temperature correction (dashed curve).

which are also plotted in the figure. However, the tabulated data involved in this way of finding $n_{\text {brine }}^{\prime}$ make it impractical for many applications.

\section{Empirical Formula}

To come up with a simpler alternative, let us try to extrapolate Quan's and Fry's empirical formula [Eq. (1)]. In order to compare the extrapolation to the measurements of Maykut and Light [3], we need temperatures and salinities of brine at freezing equilibrium. These are available from the phase equilibrium table of Assur [8] and from that of Richardson [4]. The measurements of Richardson [4] indicate that mirabilite crystals start precipitating in the brine at a temperature between $-8^{\circ} \mathrm{C}$ and $-6^{\circ} \mathrm{C}$. This causes large changes in the brine chemistry. Let us, therefore, use a parabolic, two-piece, least-squares fit to the phase equilibrium data. The two-piece fit should split at the temperature closest to where mirabilite crystals start precipitating. This temperature is not known precisely, but experimental evidence suggests a temperature closer to $-8^{\circ} \mathrm{C}$ [9-12]. The resulting fit is

$$
S= \begin{cases}6.55525-16.29630 T-0.19750 T^{2} & \text { for }-2^{\circ} \mathrm{C} \geq T \geq-8{ }^{\circ} \mathrm{C} \\ 51.59912-10.07098 T-0.10593 T^{2} & \text { for }-8{ }^{\circ} \mathrm{C}>T \geq-32^{\circ} \mathrm{C}\end{cases}
$$


where $S$ is salinity in parts per thousand (\%o) and $T$ is temperature in degrees Celsius $\left({ }^{\circ} \mathrm{C}\right)$. The fit is plotted in Fig. 2.

When the brine reaches $-22.9^{\circ} \mathrm{C}$, hydrohalite crystals $\left(\mathrm{NaCl} \cdot 2 \mathrm{H}_{2} \mathrm{O}\right)$ start precipitating. Since refractive index measurements are available down to $-32^{\circ} \mathrm{C}$, the least-squares fit should, in principle, have been a three-piece fit. The dashed curve in Fig. 2 illustrates what the third piece of the fit would look like. However, as illustrated in the following, it turns out that this closer fit to the salinity measurements at temperatures lower than $-24^{\circ} \mathrm{C}$ does not work well with Quan's and Fry's formula [Eq. (1)].

Inserting Eq. (2) for the salinity of brine in freezing equilibrium into Eq. (1), the following empirical formula results:

$$
n_{\text {brine }}^{\prime}(\lambda, T)=G_{1}(T)+\frac{G_{2}(T)}{\lambda}-\frac{4382}{\lambda^{2}}+\frac{1.1455 \cdot 10^{6}}{\lambda^{3}},
$$

where $\lambda$ is measured in nanometers and $G_{i}(T), i=1$, 2 , have the form

$$
G_{i}(T)=\alpha_{0}-\alpha_{1} T-\alpha_{2} T^{2}
$$

The coefficients are listed in Table 2 . Strictly speaking, $G_{1}(T)$ should include terms with temperature power three and four, but the coefficients are negligibly small, so these have been removed.

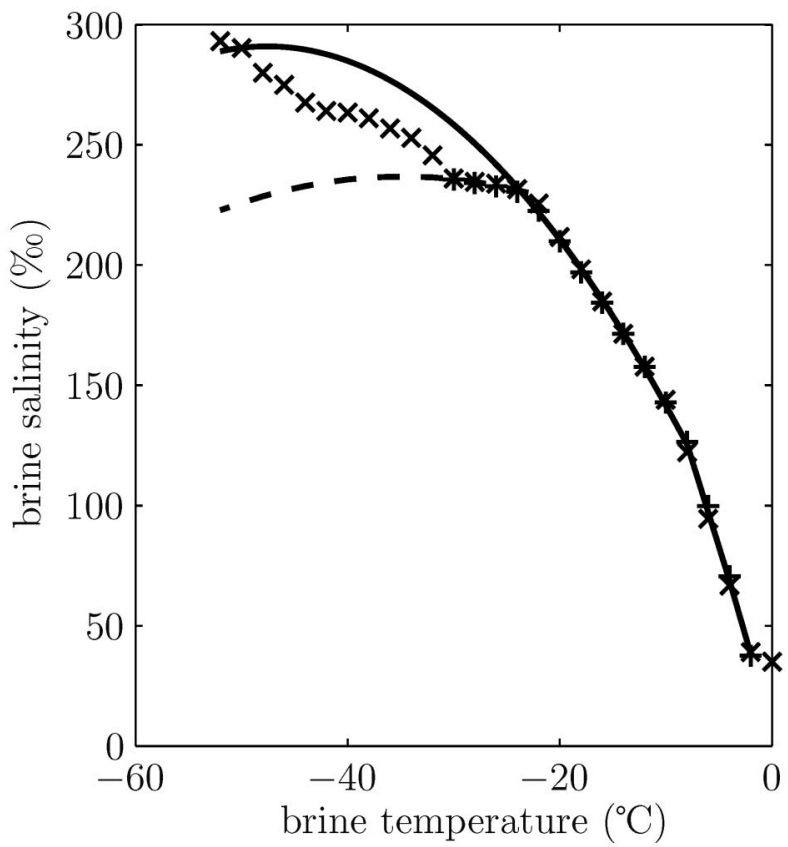

Fig. 2. Salinity of brine in freezing equilibrium as a function of temperature. Data samples measured by (+) Assur [8] and ( $x$ ) Richardson [4]. The solid curve is a two-piece, parabolic, leastsquares fit to the measurements from $-2{ }^{\circ} \mathrm{C}$ to $-8{ }^{\circ} \mathrm{C}$ and from $-8^{\circ} \mathrm{C}$ to $-24^{\circ} \mathrm{C}$. The dashed curve is a third piece fitted to the measurements from $-24^{\circ} \mathrm{C}$ to $-32^{\circ} \mathrm{C}$.
Table 2. Coefficients for the Empirical Formula Finding the Real Part of the Refractive Index of Brine $n_{\text {brine }}^{\prime}(T, \lambda)$ in Freezing Equilibrium

\begin{tabular}{ccclc}
\hline$G_{i}$ & $T\left[{ }^{\circ} \mathrm{C}\right]$ & $\alpha_{0}$ & \multicolumn{1}{c}{$\alpha_{1}$} & $\alpha_{2}$ \\
\hline$G_{1}$ & {$[-8.2,-2]$} & 1.3152 & $2.9060 \cdot 10^{-3}$ & $1.9939 \cdot 10^{-5}$ \\
$G_{1}$ & {$[-32,-8.2]$} & 1.3232 & $1.8458 \cdot 10^{-3}$ & $9.4651 \cdot 10^{-6}$ \\
$G_{2}$ & {$[-8.2,-2]$} & 15.944 & 0.19245 & $2.2811 \cdot 10^{-3}$ \\
$G_{2}$ & {$[-32,-8.2]$} & 16.464 & 0.12055 & $1.2235 \cdot 10^{-3}$ \\
\hline
\end{tabular}

The measurements by Maykut and Light [3] of the refractive index of brine in freezing equilibrium were carried out at the wavelength $\lambda=589 \mathrm{~nm}$. To check the validity of the extrapolation, $n_{\text {brine }}^{\prime}(589 \mathrm{~nm}, T)$ is plotted with the measurements in Fig. 3. The result is surprisingly accurate $\left(r^{2}=0.995\right)$. The dashed curve in Fig. 3 is the result if we had used the threepiece fit (the dashed curve in Fig. 2).

Maykut and Light [3] have also measured the refractive index of nonequilibrium brine at $T=-4{ }^{\circ} \mathrm{C}$, but with different salinities and for different wavelengths. We can use these data to check the validity of Quan's and Fry's formula further. Maykut and Light [3] only use their data to check whether the empirical formula of Schiebener et al. [5] (used with the Lorentz-Lorenz relation as noted in Section 2) provides a reasonable fit to the wavelength dependence of the refractive index of freezing brine. They do this by correcting the predicted refractive indices such that they fit the measurement for $\lambda=589 \mathrm{~nm}$. Doing the same for Eq. (1), we get the result presented in Fig. 4. The uncertainty of the measurements at

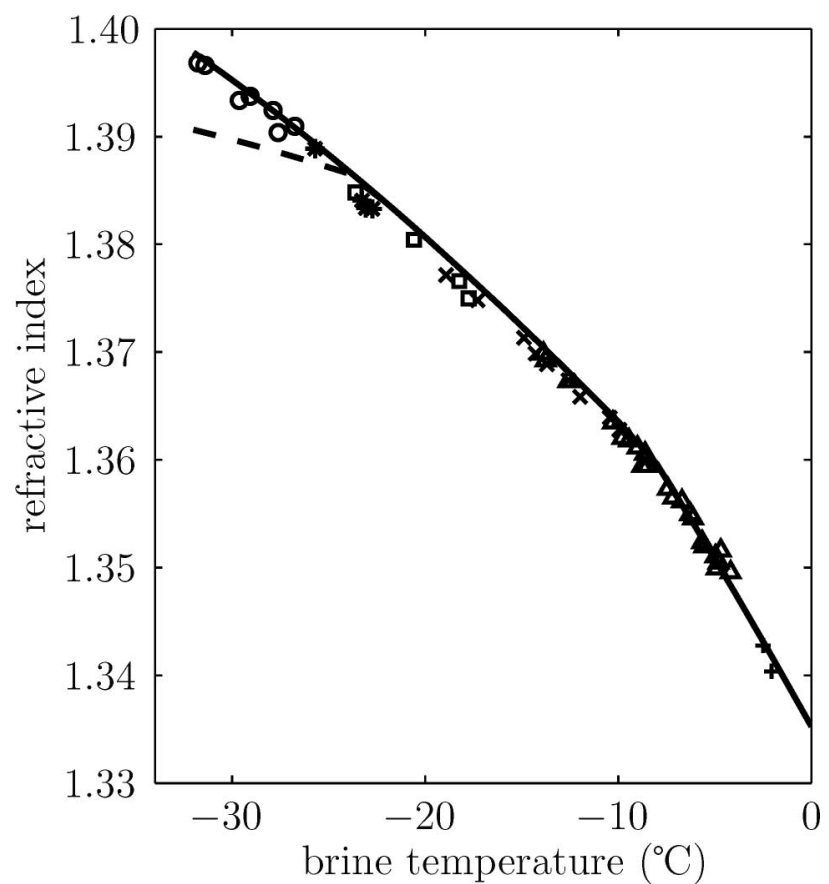

Fig. 3. Predicted refractive indices of brine in freezing equilibrium using the new extrapolation of Quan's and Fry's [1] formula (solid curve) as compared to measurements of Maykut and Light [3]. The dashed curve is the result if we use the three-piece fit in Fig. 2 instead of the two-piece fit. 


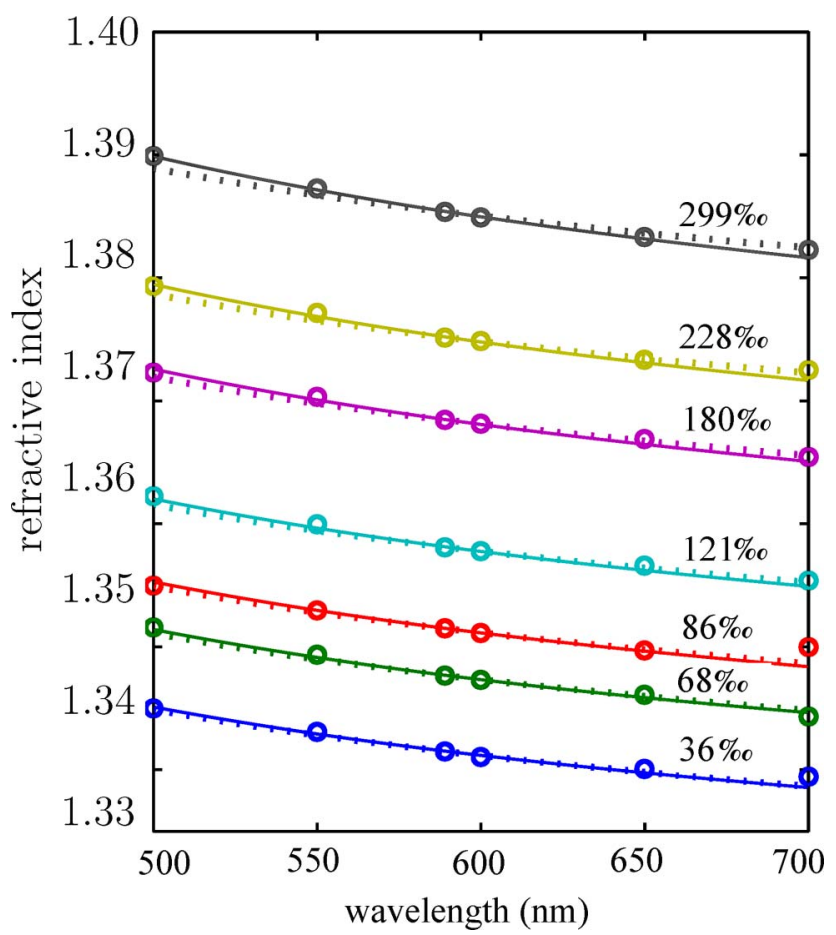

Fig. 4. (Color online) Predicted refractive indices at different wavelengths of nonequilibrium, freezing brine as compared to measurements of Maykut and Light [3]. The solid curve extrapolates the formula by Quan and Fry [1] ; the dotted curve uses the Lorentz-Lorenz relation. To explicitly check the ability to predict wavelength dependency of the refractive index, the curves have been corrected to meet the measurements at $\lambda=589 \mathrm{~nm}$.

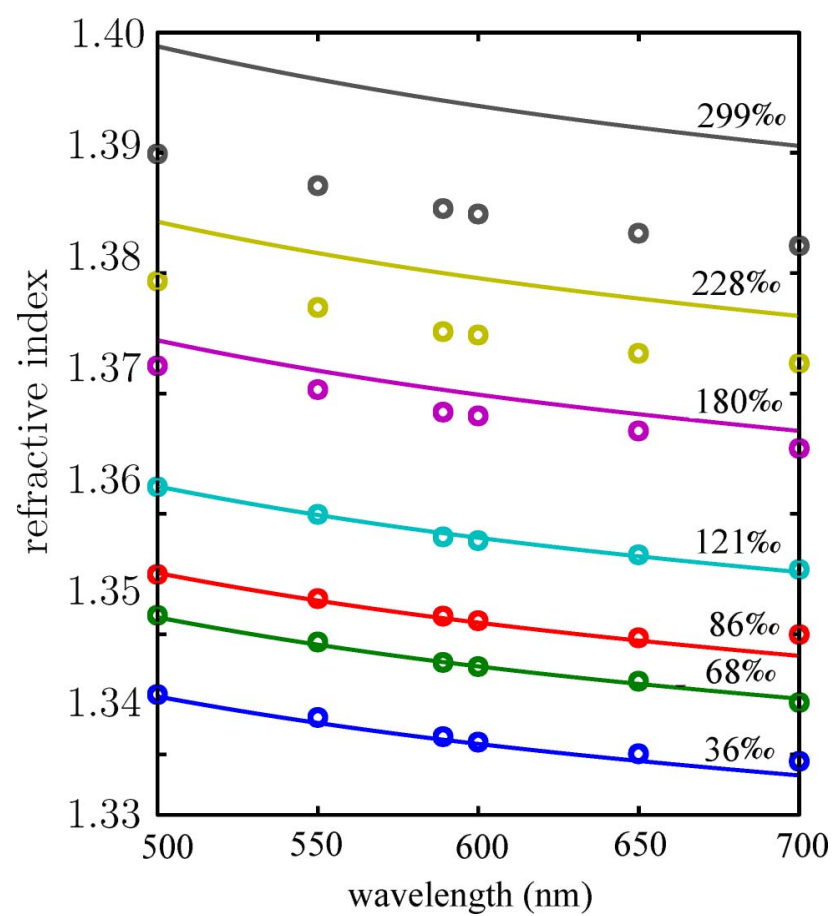

Fig. 5. (Color online) Predicted refractive indices at different wavelengths of nonequilibrium, freezing brine as compared to measurements of Maykut and Light [3] . In this figure, the curves have not been corrected. $\lambda=700 \mathrm{~nm}$ has large error bars, whereas the other measurements have error bars around the size of the marks in the plot [3]. Considering this information, Quan's and Fry's formula [Eq. (1)] seems to do a slightly better job than the formula of Schiebener et $a l$. [5] used with the Lorentz-Lorenz relation. The same is true if we do not correct the predicted curves such that they fit the measurement for $\lambda=589 \mathrm{~nm}$. This is illustrated in Fig. 5. At $S=180 \%$ and above, the Quan and Fry formula predicts increasingly too large refractive indices. Without the correction, none of the curves predicted by the Lorentz-Lorenz relation fit the measurements well. An unknown density correction is needed to make the Lorentz-Lorenz relation work for nonequilibrium brine.

\section{Discussion}

For light of wavelength $\lambda=589 \mathrm{~nm}$, Maykut and Light [3] measured the refractive index of freezing brine in phase equilibrium $\left(-32^{\circ} \mathrm{C} \leq T \leq-2{ }^{\circ} \mathrm{C}\right)$. For light of various wavelengths, they also measured the refractive index of freezing nonequilibrium brine at $T=-4{ }^{\circ} \mathrm{C}(36 \%$ o $S \leq 299 \%)$. Comparison to these measurements indicates that extrapolation of the empirical formula by Quan and Fry [1] is a good approximation for temperatures down to $-24^{\circ} \mathrm{C}$ and salinities up to $180 \%$.

Figure 4 confirms that Quan's and Fry's formula reliably describes the wavelength dependency of freezing brine from 500 to $700 \mathrm{~nm}$. This means that the formula is most probably accurate for freezing brine in the entire spectrum from 200 to $1100 \mathrm{~nm}$ as tested by Huibers [2] for nonfreezing brine.

There is a short range of temperatures $\left(-2{ }^{\circ} \mathrm{C}<T<0{ }^{\circ} \mathrm{C}\right)$ where refractive index measurements are not available for the brine. Consequently, it is not certain whether Quan's and Fry's formula is valid in this range. However, since the temperature of maximum density and the freezing point of the brine is close to $-2{ }^{\circ} \mathrm{C}$ [7], the refractive index will not change much in this range and nor will the salinity. Small changes in salinity and temperatures close to zero mean that Quan's and Fry's formula will not change much either in this range. Then, as the formula is valid for both $-2{ }^{\circ} \mathrm{C}$ and $0{ }^{\circ} \mathrm{C}$, it is quite probable that it is valid in the entire range of temperatures from $-24^{\circ} \mathrm{C}$ to $30^{\circ} \mathrm{C}$.

As illustrated by the dashed curve in Fig. 3, Quan's and Fry's formula has problems below $-24^{\circ} \mathrm{C}$ if we use a closer fit to the salinity measurements. This is not surprising since hydrohalite, which starts precipitating at $-22.9^{\circ} \mathrm{C}$, is by far the most abundant salt in brine.

Incidentally, for freezing brine in phase equilibrium, the presented empirical formula [Eq. (3)] provides a good approximation for temperatures all the way down to $-32{ }^{\circ} \mathrm{C}$ (where the salinity is also larger than 180\%o). To broaden the applicability of Quan's and Fry's formula even further, a density correction is probably needed for brine of very high salinity. 


\section{References}

1. X. Quan and E. S. Fry, "Empirical equation for the index of refraction of seawater," Appl. Opt. 34, 3477-3480(1995).

2. P. D. T. Huibers, "Models for the wavelength dependence of the index of refraction of water," Appl. Opt. 36, 3785-3787 (1997).

3. G. A. Maykut and B. Light, "Refractive-index measurements in freezing sea-ice and sodium chloride brines," Appl. Opt. 34, 950-961 (1995).

4. C. Richardson, "Phase relationships in sea ice as a function of temperature," J. Glaciol. 17, 507-519 (1976).

5. P. Schiebener, J. Straub, J. M. H. L. Sengers, and J. S. Gallagher, "Refractive index of water and steam as function of wavelength, temperature and density," J. Phys. Chem. Ref. Data 19, 677-717 (1990).

6. A. W. Stelson, "Urban aerosol refractive index prediction by partial molar refraction approach," Environ. Sci. Technol. 24, 1676-1679 (1990).

7. T. G. Thompson and K. H. Nelson, "Concentration of brines and deposition of salts from sea water under frigid conditions," Am. J. Sci. 254, 227-238 (1956).
8. A. Assur, "Composition of sea ice and its tensile strength," in Arctic Sea Ice, National Research Council Publication 598 (U. S. National Academy of Sciences, 1958), pp. 106-138.

9. W. E. Ringer, "Ueber die Veränderungen in der Zusammensetzung des Meereswassersalzes beim Ausfrieren," Verhandelingen uit het Rijksinstituut voor het Onderzoek der Zee 1, 155 (1906).

10. K. E. Gitterman, "Thermal analysis of sea water," Trudy Solyanoi Laboratorii Akademii Nauk SSSR 15, 5-32 (1937); Translated in Tech. Rep. CRREL TL 287 (U. S. Army Cold Regions Research and Engineering Laboratory, 1971).

11. K. H. Nelson and T. G. Thompson, "Deposition of salts from sea water by frigid concentration," Tech. Rep. 29 (Department of Oceanography, University of Washington, 1954).

12. G. M. Marion, R. E. Farren, and A. J. Komrowski, "Alternative pathways for seawater freezing," Cold Reg. Sci. Technol. 29, 259-266 (1999). 